\title{
Effect of EGR on the exhaust gas temperature and exhaust opacity in compression ignition engines
}

\author{
AVINASH KUMAR AGRAWAL*1, SHRAWAN KUMAR SINGH ${ }^{2}$, \\ SHAILENDRA SINHA ${ }^{1}$ and MRITUNJAY KUMAR SHUKLA ${ }^{1}$ \\ ${ }^{1}$ Department of Mechanical Engineering, and \\ ${ }^{2}$ Environmental Engineering and Management, Indian Institute of Technology, \\ Kanpur 208 016, India \\ *e-mail: akag@iitk.ac.in
}

MS received 27 January 2003; revised 8 September 2003

\begin{abstract}
In diesel engines, NOx formation is a highly temperature-dependent phenomenon and takes place when the temperature in the combustion chamber exceeds $2000 \mathrm{~K}$. Therefore, in order to reduce NOx emissions in the exhaust, it is necessary to keep peak combustion temperatures under control.

One simple way of reducing the NOx emission of a diesel engine is by late injection of fuel into the combustion chamber. This technique is effective but increases fuel consumption by 10-15\%, which necessitates the use of more effective NOx reduction techniques like exhaust gas recirculation (EGR). Re-circulating part of the exhaust gas helps in reducing NOx, but appreciable particulate emissions are observed at high loads, hence there is a trade-off between NOx and smoke emission. To get maximum benefit from this trade-off, a particulate trap may be used to reduce the amount of unburnt particulates in EGR, which in turn reduce the particulate emission also.

An experimental investigation was conducted to observe the effect of exhaust gas re-circulation on the exhaust gas temperatures and exhaust opacity. The experimental setup for the proposed experiments was developed on a two-cylinder, direct injection, air-cooled, compression ignition engine. A matrix of experiments was conducted for observing the effect of different quantities of EGR on exhaust gas temperatures and opacity.
\end{abstract}

Keywords. Diesel engine; EGR; NOx; pollution.

\section{Introduction}

Over recent past years, stringent emission legislations have been imposed on NOx, smoke and particulate emissions emitted from automotive diesel engines world wide. Diesel engines are typically characterized by low fuel consumption and very low $\mathrm{CO}$ emissions. However, the NOx emissions from diesel engines still remain high. Hence, in order to meet the environmental legislations, it is highly desirable to reduce the amount of NOx in the exhaust gas. 
Diesel engines are predominantly used to drive tractors, heavy lorries and trucks. Owing to their low fuel consumption, they have become increasingly attractive for smaller lorries and passenger cars also. But higher NOx emissions from diesel engine remain a major problem in the pollution aspect.

For reducing vehicular emissions, baseline technologies are being used which include direct injection, turbo-charging, air-to-air inter-cooling, combustion optimization with and without swirl support, multi-valve cylinder head, advanced high pressure injection system i.e. split injection or rate shaping, electronic management system, lube oil consumption control etc. However, technologies like exhaust gas recirculation (EGR), soot traps and exhaust gas aftertreatment are essential to cater to the challenges posed by increasingly stringent environmental emission legislations.

\subsection{Mechanism of NOx formation}

A major hurdle in understanding the mechanism of formation and controlling its emission is that combustion is highly heterogeneous and transient in diesel engines.

While $\mathrm{NO}$ and $\mathrm{NO}_{2}$ are lumped together as $\mathrm{NOx}$, there are some distinctive differences between these two pollutants. $\mathrm{NO}$ is a colourless and odourless gas, while $\mathrm{NO}_{2}$ is a reddishbrown gas with pungent odour. Both gases are considered toxic, but $\mathrm{NO}_{2}$ has a level of toxicity 5 times greater than that of $\mathrm{NO}$. Although $\mathrm{NO}_{2}$ is largely formed from oxidation of $\mathrm{NO}$, attention has been given on how NO can be controlled before and after combustion (Levendis et al 1994).

$\mathrm{NO}$ is formed during the post flame combustion process in a high temperature region. The most widely accepted mechanism was suggested by Zeldovich (Heywood 1988). The principal source of NO formation is the oxidation of the nitrogen present in atmospheric air. The nitric oxide formation chain reactions are initiated by atomic oxygen, which forms from the dissociation of oxygen molecules at the high temperatures reached during the combustion process. The principal reactions governing the formation of NO from molecular nitrogen are,

$$
\begin{gathered}
\mathrm{N}_{2}+\mathrm{O} \rightarrow \mathrm{NO}+\mathrm{N}, \\
\mathrm{N}+\mathrm{O}_{2} \rightarrow \mathrm{NO}+\mathrm{O}, \\
\mathrm{N}+\mathrm{OH} \rightarrow \mathrm{NO}+\mathrm{H} .
\end{gathered}
$$

Chemical equilibrium consideration indicates that for burnt gases at typical flame temperatures, $\mathrm{NO}_{2} / \mathrm{NO}$ ratios should be negligibly small. While experimental data show that this is true for spark ignition engines, in diesels, $\mathrm{NO}_{2}$ can be 10 to $30 \%$ of total exhaust emissions of oxides of nitrogen. A plausible mechanism for the persistence of $\mathrm{NO}_{2}$ is as follows. $\mathrm{NO}$ formed in the flame zone can be rapidly converted to $\mathrm{NO}_{2}$ via reactions such as

$$
\mathrm{NO}+\mathrm{HO}_{2} \rightarrow \mathrm{NO}_{2}+\mathrm{OH}
$$

Subsequently, conversion of this $\mathrm{NO}_{2}$ to $\mathrm{NO}$ occurs via

$$
\mathrm{NO}_{2}+\mathrm{O} \rightarrow \mathrm{NO}+\mathrm{O}_{2}
$$

unless the $\mathrm{NO}_{2}$ formed in the flame is quenched by mixing with cooler fluid. This explanation is consistent with the highest $\mathrm{NO}_{2} / \mathrm{NO}$ ratio occurring at high load in diesels, when cooler regions which could quench the conversion back to NO are widespread wood 1988). 
The local atomic oxygen concentration depends on molecular oxygen concentration as well as local temperatures. Formation of NOx is almost absent at temperatures below $2000 \mathrm{~K}$. Hence any technique, that can keep the instantaneous local temperature in the combustion chamber below $2000 \mathrm{~K}$, will be able to reduce NOx formation.

\section{EGR technique for NOx reduction}

EGR is a useful technique for reducing NOx formation in the combustion chamber. Exhaust consists of $\mathrm{CO}_{2}, \mathrm{~N}_{2}$ and water vapours mainly. When a part of this exhaust gas is re-circulated to the cylinder, it acts as diluent to the combusting mixture. This also reduces the $\mathrm{O}_{2}$ concentration in the combustion chamber. The specific heat of the EGR is much higher than fresh air, hence EGR increases the heat capacity (specific heat) of the intake charge, thus decreasing the temperature rise for the same heat release in the combustion chamber,

$$
\% \mathrm{EGR}=\frac{\text { volume of EGR }}{\text { total intake charge into the cyclinder }} \times 100 .
$$

Another way to define the EGR ratio is by the use of $\mathrm{CO}_{2}$ concentration (Baert et al 1999),

$$
\text { EGR ratio }=\frac{\left[\mathrm{CO}_{2}\right]_{\text {intake }}-\left[\mathrm{CO}_{2}\right]_{\text {ambient }}}{\left[\mathrm{CO}_{2}\right]_{\text {exhaust }}-\left[\mathrm{CO}_{2}\right]_{\text {ambient }}} .
$$

Three popular explanations for the effect of EGR on NOx reduction are increased ignition delay, increased heat capacity and dilution of the intake charge with inert gases. The ignition delay hypothesis asserts that because EGR causes an increase in ignition delay, it has the same effect as retarding the injection timing. The heat capacity hypothesis states that the addition of the inert exhaust gas into the intake increases the heat capacity (specific heat) of the nonreacting matter present during the combustion. The increased heat capacity has the effect of lowering the peak combustion temperature. According to the dilution theory, the effect of EGR on NOx is caused by increasing amounts of inert gases in the mixture, which reduces the adiabatic flame temperature (Pierpont et al 1995).

At high loads, it is difficult to employ EGR due to deterioration in diffusion combustion and this may result in an excessive increase in smoke and particulate emissions. At low loads, unburnt hydrocarbons contained in the EGR would possibly re-burn in the mixture, leading to lower unburnt fuel in the exhaust and thus improved brake thermal efficiency. Apart from this, hot EGR would raise the intake charge temperature, thereby influencing combustion and exhaust emissions.

With the use of EGR, there is a trade-off between reduction in NOx and increase in soot, CO and unburnt hydrocarbons. A large number of studies have been conducted to investigate this. It is indicated that for more than 50\% EGR, particulate emissions increase significantly, and therefore use of a particulate trap is recommended. The change in oxygen concentration causes change in the structure of the flame and hence changes the duration of combustion. It is suggested that flame temperature reduction is the most important factor influencing NO formation.

Figure 1 shows the reduction in NOx emission due to EGR at different loads. Implementation of EGR in diesel engines has problems like (a) increased soot emission, (b) introduction of particulate matter into the engine cylinders. When the engine components come into contact with high velocity soot particulates, particulate abrasion may occur. Sulphuric acid and condensed water in EGR also cause corrosion. Some studies have detected damage on the 


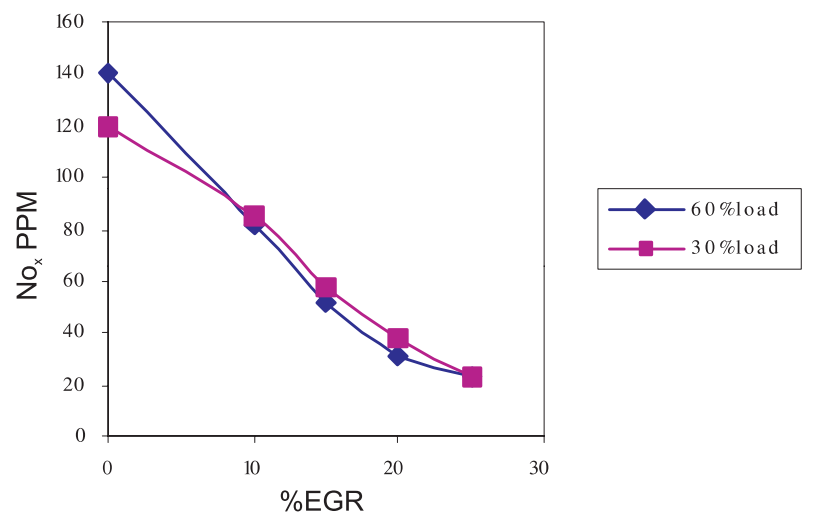

Figure 1. Effect of EGR on NOx (Mehta et al 1994).

cylinder walls due to the reduction in the oil's lubrication capacity, which is hampered due to the mixing of soot carried with the particulate laden recirculated exhaust gas. This necessitates the use of an efficient particular trap (Mehta et al 1994).

Studies have shown that EGR coupled with a high collection-efficiency particulate trap, controls smoke, unburnt hydrocarbon and NOx emissions simultaneously. The particulate trap, however, needs to be regenerated since its pores get clogged by the trapped soot particles. Clogged soot traps increase backpressure to the engine exhaust, thus affecting engine performance also. These traps need to be regenerated from time to time using thermal or aerodynamic or electrostatic regeneration techniques. Other methods of reducing the particulate emission from diesel engines include multiple injections, supercharging and higher fuel injection pressure etc. The highest attention is currently being paid to two self-regenerating systems: fuel additive-supported regeneration by using cerium- or iron-based additives, and a continuous regeneration trap (CRT) using sulphur-free diesel fuel (Zelenka et al 1998).

During the last 20 years, plenty of research work has been done on EGR and its effects on the engine performance in terms of fuel efficiency, volumetric efficiency, power generated etc. These studies have been carried out at various loads, engine speed and variable engine parameters like temperature and pressure, compression ratio etc.

\section{Classification of EGR systems}

Various EGR systems have been classified on the basis of EGR temperature, configuration and pressure.

\subsection{Classification based on temperature}

(i) Hot EGR: Exhaust gas is recirculated without being cooled, resulting in increased intake charge temperature.

(ii) Fully cooled EGR: Exhaust gas is fully cooled before mixing with fresh in take air using a water-cooled heat exchanger. In this case, the moisture present in the exhaust gas may condense and the resulting water droplets may cause undesirable effects inside the engine cylinder.

(iii) Partly cooled EGR: To avoid water condensation, the temperature of the exhaust gas is kept just above its dew point temperature. 


\subsection{Classification based on configuration}

(i) Long route system $(L R)$ : In an LR system the pressure drop across the air intake and the stagnation pressure in the exhaust gas stream make the EGR possible. The exhaust gas velocity creates a small stagnation pressure, which in combination with low pressure after the intake air, gives rise to a pressure difference to accomplish EGR across the entire torque/speed envelop of the engine.

(ii) Short route system $(S R)$ : These systems differed mainly in the method used to set up a positive pressure difference across the EGR circuit.

Another way of controlling the EGR-rate is to use variable nozzle turbine (VNT). Most of the VNT systems have single entrance, which reduce the efficiency of the system by exhaust pulse separation. Cooled EGR should be supplied effectively. Lundquist and others used a variable venturi, in which EGR-injector was allowed to move axially, thus varying the critical area was used (Lundquist et al 2000).

\subsection{Classification based on pressure}

Two different routes for EGR, namely low-pressure and high-pressure route systems may be used (Kohketsu et al 1997).

(i) Low pressure route system: The passage for EGR is provided from downstream of the turbine to the upstream side of the compressor.

It is found that by using the low pressure route method, EGR is possible up to a high load region, with significant reduction in $\mathrm{NO}_{\mathrm{x}}$. However, some problems occur, which influence durability, prohibitionary high compressor outlet temperature and intercooler clogging.

(ii) High pressure route system: The EGR is passed from upstream of the turbine to downstream of the compressor.

In the high pressure route EGR method, although EGR is possible in the high load regions, the excess air ratio decreases and fuel consumption increases remarkably.

\section{Experimental setup}

A two-cylinder constant speed diesel engine generator set is used in present investigations. It is an air-cooled, vertical, direct-injection, four-stroke, compression-ignition engine. Specifications of the engine are as given in table 1.

Table 1. Specifications of the engine.

\begin{tabular}{lc}
\hline Type of injection: & Direct \\
Engine manufacturer: & INDEC Engines Ltd. \\
No. of cylinders: & 2 \\
Bore/stroke: & $87 \cdot 3 \mathrm{~mm} / 110 \mathrm{~mm}$ \\
Max. power/engine speed: & $12.5 \mathrm{bhp}(9 \cdot 3 \mathrm{~kW}) / 1500$ \\
Compression ratio: & $16 \cdot 5: 1$ \\
Displacement: & $1323 \mathrm{~cm}^{3}$ \\
\hline
\end{tabular}




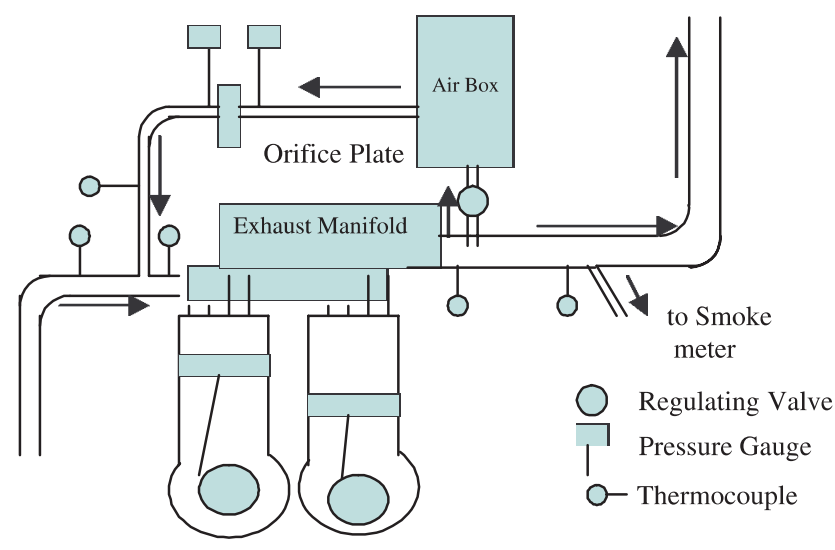

Figure 2. Line diagram of the proposed EGR system.

At the rated speed (1500 RPM), the engine develops approximately $9 \mathrm{~kW}$ power output. The inlet valve opens at $4.5^{\circ} \mathrm{BTDC}$ and closes at $35.5^{\circ} \mathrm{ABDC}$. The exhaust valve opens at $35.5^{\circ} \mathrm{BBDC}$ and closes at $4.5^{\circ}$ ATDC. The engine is coupled with a single-phase, 220 volts AC generator. A load bank of $10 \mathrm{~kW}$ with a step of $500 \mathrm{~W}$ is used for loading the enginegenset system.

The objective of developing this experimental test setup is to investigate and demonstrate the effects of various EGR rates and other engine parameters on exhaust emissions from the engine. A long route partially cooled EGR system is chosen based on its merits. Several components of this EGR system have been designed and fabricated.

An air box is designed to measure the volumetric flow rate of intake air to the engine. It is mounted on the inlet pipe between the air filter and the inlet manifold of the engine as shown in figure 2. The air box dampens out the fluctuations of the intake air. A diaphragm is provided on the side of the air box for dampening out the local undulations effectively. The air box is fitted with an orifice (shown in figure 3 ) for volumetric flow rate measurement of air. A U-tube manometer is mounted across the orifice, to measure the pressure difference inside the air box and the atmosphere (Stearn et al 1951). The coefficient of discharge of the orifice is found experimentally to be 0.602 .

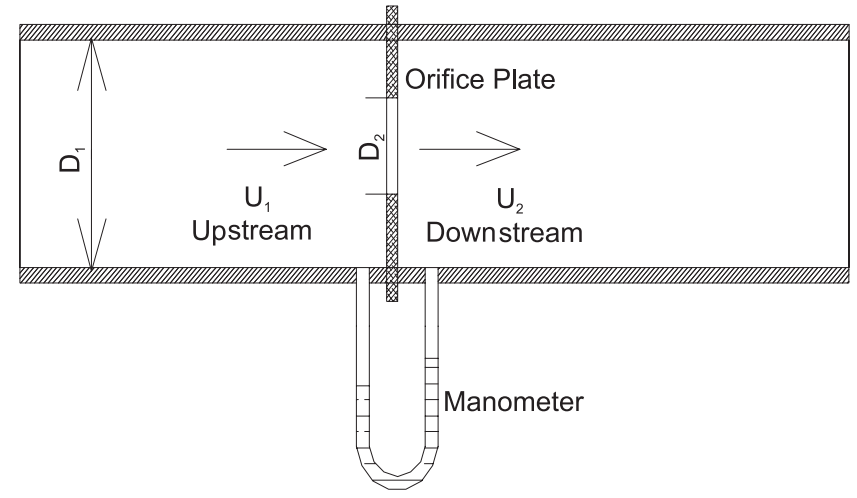

Figure 3. A schematic diagram of orifice meter. 


\subsection{Recirculation system}

Part of the exhaust gas is to be recirculated and put back to the combustion chamber along with the intake air. The quantity of this EGR is to be measured and controlled accurately, hence a by-pass for the exhaust gas is provided along with the manually controlled EGR valve.

The exhaust gas comes out of the engine during the exhaust stroke at high pressure. It is pulsating in nature. It is desirable to remove these pulses in order to make the volumetric flow rate measurements of the recirculating gas possible. For this purpose, another smaller air box with a diaphragm is installed in the EGR route. An orifice meter is designed and installed to measure the volumetric flow rate of the EGR.

The detailed schematic line drawing of the experimental EGR system is shown in figure 2. A U-tube manometer is mounted across the orifice in order to measure the EGR flow rate. Suitable instrumentation is provided to acquire useful data from various locations. Thermocouples are provided at the intake manifold, exhaust manifold and various points along the EGR route.

An AVL smoke-meter is used to measure the smoke opacity of the exhaust gas. The pressure difference across the orifice is used to calculate the EGR rate. A matrix of test conditions is used to investigate the effect of EGR on exhaust gas temperature and exhaust smoke opacity.

\section{Results and discussion}

At fixed power conditions, as the percentage EGR increases (0-21\%), the temperature of the exhaust gas continuously decreases. This is shown in figure 4.

Earlier it was mentioned that the most important reason for the formation of NOx in the combustion chamber is extremely high temperature. Our experimental results indicate (figure 4) a decrease in the exhaust temperatures with increasing EGR, therefore it can be safely concluded that the combustion chamber temperatures also decrease and thus the formation of NOx is decreased.

This reduction in exhaust gas temperature does not affect the thermal efficiency. From figure 5, it is clear that thermal efficiency remains unaffected by EGR. However, at high loads

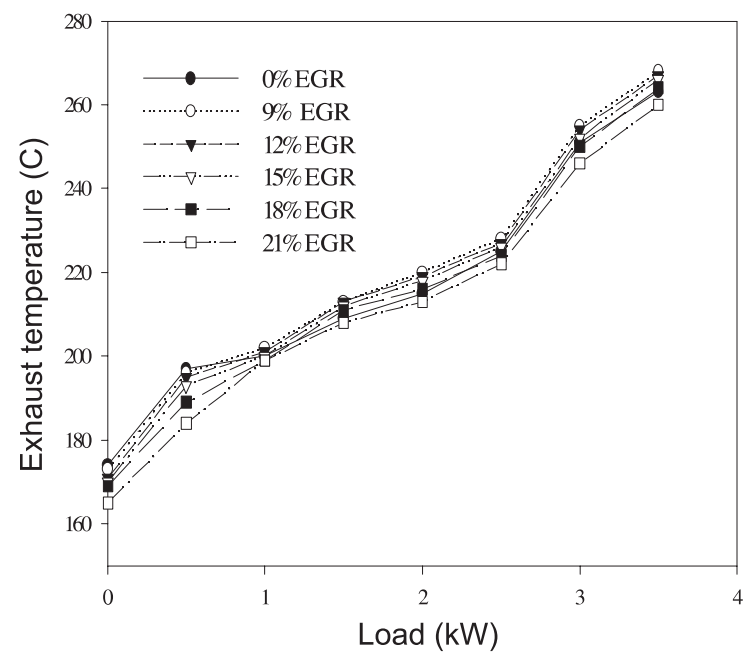

Figure 4. Exhaust gas temperature vs load at constant EGR. 


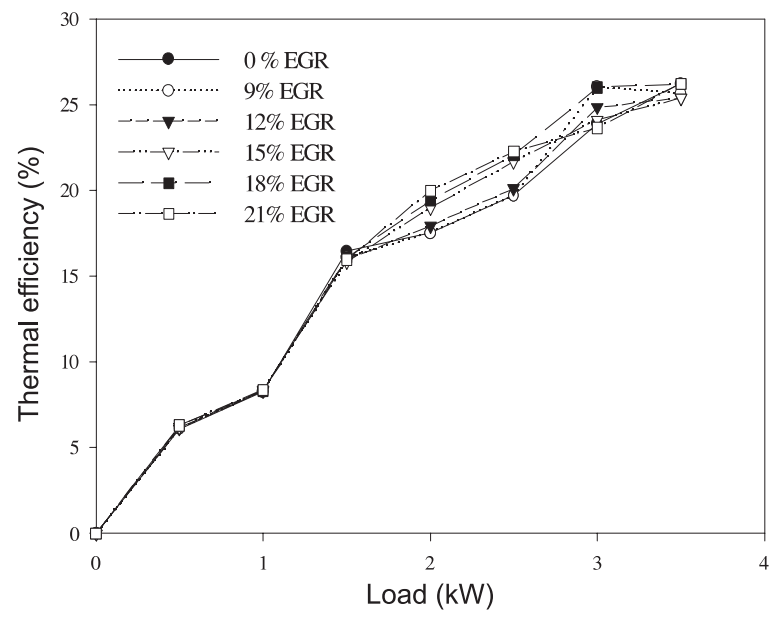

Figure 5. Thermal efficiency vs load at constant EGR.

and at EGR rates above $15 \%$, thermal efficiency tends to decrease slightly. This may be due to the fact that the amount of fresh oxygen available for combustion gets decreased due to replacement by exhaust gas.

Opacity of the exhaust gas increases as the rate of EGR is increased. At low loads, the rate of increase in opacity is almost the same with increase in EGR but at higher loads and higher rates of EGR, opacity increases rapidly, as shown in figure 6. Further it was also found that the brake specify fuel consumption (BSFC) is fairly independent of EGR (figure 7). As load increases, BSFC decreases rapidly. At $3 \mathrm{~kW}$ the BSFC gets almost saturated at $0 \cdot 22 \mathrm{~kg} / \mathrm{kW}$.

\section{Conclusion}

An experimental set-up to measure the effects of exhaust gas recirculation on engine characteristics like exhaust gas temperature, thermal efficiency, brake specific fuel consumption and

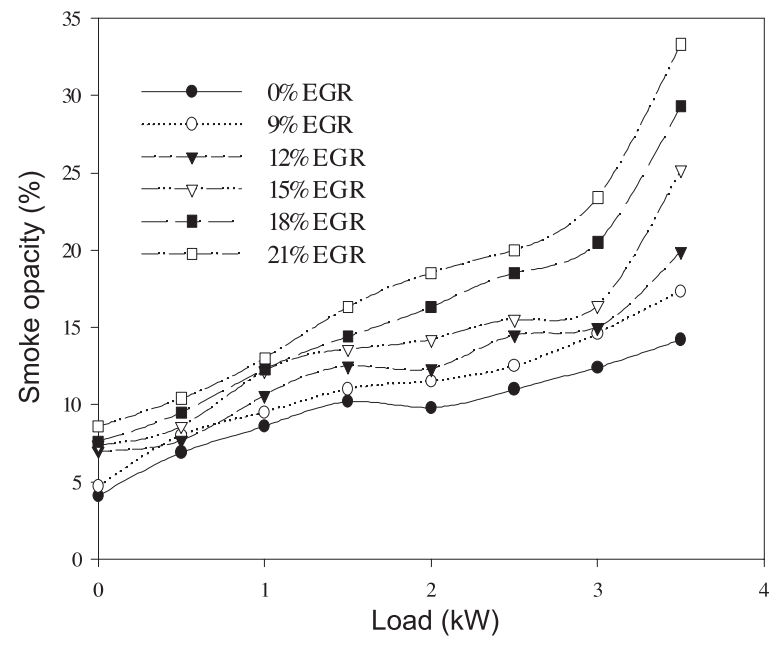

Figure 6. Smoke opacity in exhaust gas vs load at constant EGR. 


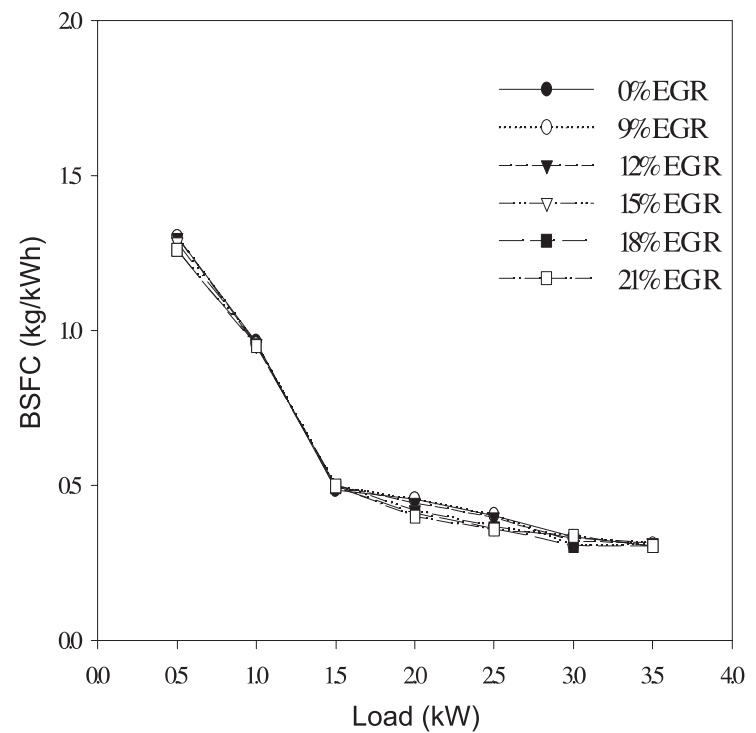

Figure 7. BSFC vs load at constant EGR.

smoke opacity has been developed. Experiments were carried out using the setup to prove the efficacy of EGR as a technique for NOx reduction. It is seen that the exhaust gas temperatures reduce drastically by employing EGR. This indirectly shows the potential for reduction of NOx emission. This can be concluded from the fact that the most important reason for the formation of NOx in the combustion chamber is the high temperature of about $2000 \mathrm{~K}$ at the site of combustion.

Thermal efficiency and brake specific fuel consumption are not affected significantly by EGR. However particulate matter emission in the exhaust increases, as evident from smoke opacity observations.

Diesel engines score higher than that of other engines in most aspects like fuel consumption and low $\mathrm{CO}$ emissions, but loses in $\mathrm{NO}_{\mathrm{x}}$ emissions. EGR is proved to be one of the most efficient methods of NOx reduction in diesel engines. The increase in particulate matter emissions due to EGR can be taken care by employing particulate traps and adequate regeneration techniques.

Our sincere thanks to the staff of the Energy Conversion Laboratory, Department of Mechanical Engineering for their cooperation and assistance in setting up the experimental set-up and their help in performing experimental investigation.

\section{References}

Baert R S G, Beckman D E, Veen A 1999 Efficient EGR technology for future HD diesel engine emission targets. SAE 1999-01-0837

Heywood J B 1988 Pollutant formation and control. Internal combustion engine fundamentals Int. edn (New York: Mc-Graw Hill) pp 572-577

Kohketsu S, Mori K, Sakai K, Hakozaki T 1997 EGR technologies for a turbocharged and inter-cooled heavy-duty diesel engine. SAE 970347 
Levendis Y A, Pavalatos I, Abrams R F 1994 Control of diesel soot hydrocarbon and NOx emissions with a particular trap. SAE 940460

Lundquist U, Smedler G, Stalhammar P 2000 A comparison between different EGR systems for HD diesel engines and their effects on performance, fuel consumption and emissions. SAE 2000-010226

Mehta S, Oey F, Sumbung C L, Levendis Y A 1994 An aerodynamically regenerated diesel particulate trap with a flow-through soot incinerator section. SAE 940461

Pierpont D A, Montgomery D T, Reitz R D 1995 Reducing particulate and NOx using multiple injections and EGR in a D. I. diesel. SAE 950217

Sher E 1998 Motor vehicle emissions control: Past achievements, future prospects. Handbook of air pollution from IC engines pollutant formation and control (San Diego, CA: Academic Press) pp 9-10

Stearns R F, Johnson R R, Jackson R M, Larson C A 1951 Derivation of flow equations. Flow measurements with orifice meters (Princeton, N J: D V N Com.) p-4

Zelenka P, Aufinger H, Reczek W, Cartellieri W 1998 Cooled EGR-A technology for future efficient HD diesels. SAE 980190 